\title{
Mediterranean hurricanes: large-scale environment and convective and precipitating areas from satellite microwave observations
}

\author{
C. Claud $^{1}$, B. Alhammoud ${ }^{1}$, B. M. Funatsu ${ }^{1}$, and J.-P. Chaboureau ${ }^{2}$ \\ ${ }^{1}$ Laboratoire de Météorologie Dynamique/IPSL, CNRS, UMR8539, Ecole Polytechnique, Palaiseau, France \\ ${ }^{2}$ Laboratoire d'Aérologie, University of Toulouse and CNRS, Toulouse, France
}

Received: 21 May 2010 - Revised: 10 September 2010 - Accepted: 11 October 2010 - Published: 29 October 2010

\begin{abstract}
Subsynoptic scale vortices that have been likened to tropical cyclones or polar lows (medicanes) are occasionally observed over the Mediterranean Sea. Generated over the sea, they are usually associated with strong winds and heavy precipitation and thus can be highly destructive in islands and costal areas. Only an accurate forecasting of such systems could mitigate these effects. However, at the moment, the predictability of these systems remains limited.

Due to the scarcity of conventional observations, use is made of NOAA/MetOp satellite observations, for which advantage can be taken of the time coverage differences between the platforms that carry it, to give a very complete temporal description of the disturbances. A combination of AMSU-B (Advanced Microwave Sounding Unit-B)/MHS (Microwave Humidity Sounder) observations permit to investigate precipitation associated with these systems while coincident AMSU-A (Advanced Microwave Sounding UnitA) observations give insights into the larger synoptic-scale environment in which they occur.

Three different cases (in terms of intensity, location, trajectory, duration, and periods of the year - May, September and December, respectively) were investigated. Throughout these time periods, AMSU-A observations show that the persisting deep outflow of cold air over the sea together with an upper-level trough upstream constituted a favourable environment for the development of medicanes. AMSUB/MHS based diagnostics show that convection and precipitation areas are large in the early stage of the low, but significantly reduced afterwards. Convection is maximum just after the upper-level trough, located upstream of cold midtropospheric air, reached its maximum intensity and acquired a cyclonic orientation.
\end{abstract}

Correspondence to: C. Claud (chclaud@1md.polytechnique.fr)

\section{Introduction}

It has been long recognized that hurricane-like cyclones can sometimes form over the Mediterranean (Ernst and Matson, 1983; Billing et al., 1983) where they are referred to as medicanes (Mediterranean "hurricanes"). Their structure, as revealed by satellite imagery, is often similar to tropical cyclones with a clear and quasi-circular eye surrounded by an eyewall and a roughly axisymmetric cloud pattern (see Fig. 1). They are however of smaller size (a few hundreds kilometres at most) and the typical environment in which they form is different: while tropical cyclones occur in regions characterized by moist conditions, medicanes occur in much drier environment (e.g. Fita et al., 2007a). The vertical profile of the atmosphere, i.e. the presence of cold air at middle and upper levels, combined with rather warm Sea Surface Temperature (SST) and boundary layer (Reed et al., 2001; Emanuel, 2005; Fita et al., 2007a), plays a crucial role in their development. This explains why these systems have also been compared to polar lows (Rasmussen and Zick, 1987). These high-latitude intense mesoscale disturbances that form when very cold air is advected over relatively warm water (e.g. Heinemann and Claud, 1997) are characterized by large differences between SST and the temperature in the mid-troposphere (e.g. Claud et al., 2007, Zahn and van Storch, 2007, Blechschmidt et al., 2009). Businger and Reed (1989) even considered these Mediterranean storms as a particular case of polar lows, namely the cold-low type.

Medicane case studies have generally focused on the role of convective instability (Pytharoulis et al., 2000, Lagouvardos et al., 1999 among others) as opposed to baroclinic instability, even if the way by which convective instability is produced is still debated. Orography has also been found to play a role in some cases (e.g. Alpert et al., 1999). In addition, the role of upper-level forcing for the Mediterranean

Published by Copernicus Publications on behalf of the European Geosciences Union. 

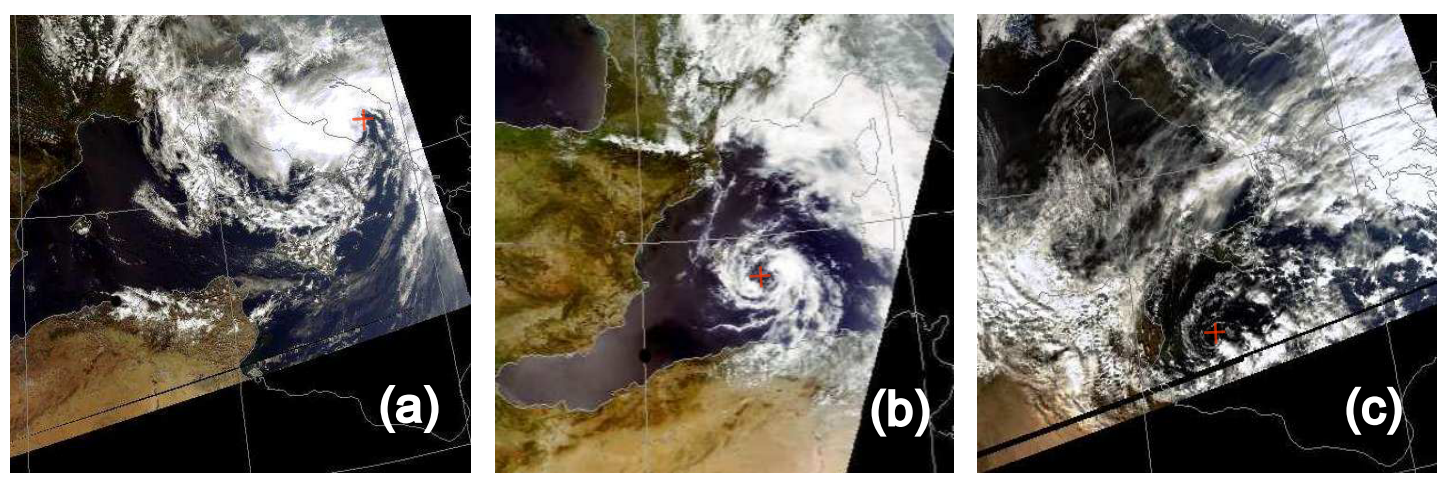

Fig. 1. MODIS satellite composite images (http://www.sat.dundee.ac.uk) of the three medicanes considered in this study: (a) 26 September 2006, 12:45 UTC, (b) 27 May 2003, 11:09 UTC, (c) 14 December 2005, 12:29 UTC. Red crosses indicate the position of the medicanes.

low-level cyclogenesis (medicanes or not) has been underlined by a number of studies (e.g. Doswell et al., 1998; Reale and Atlas, 2001; Romero, 2001; Homar et al., 2002, 2003; Chaboureau and Claud, 2006; Fita et al., 2007b; Funatsu et al., 2008, 2009).

Despite our knowledge of the necessary key ingredients for medicanes formation, their predictability is still limited because there is a large range of processes that play a role, as well as uncertainties of the system due to the inherent nonlinearity of the atmospheric dynamics and the several scale interactions. Their small scale extent added to the absence or rareness of synoptic observations in the areas where they develop also contribute to a rather poor forecasting skill. In this sense, there has been an increased interest in identifying and quantifying the sources of uncertainties that affect the forecast and climate projection in the Mediterranean region. It is thus important to have a description as accurate as possible of these high-impact weather systems and of the environment in which they develop.

This work aims at contributing to this effort, more specifically, to better characterize the precipitation fields and the large-scale environment (upper-level and mid-troposphere) of medicanes. To this end, we use the satellite data provided by the Advanced Microwave Sounding Unit (AMSU) radiometer to detect moderate and heavy precipitating areas associated with medicanes and their embedded mid- and uppertropospheric environment. We take advantage of the fact that AMSU observations first, are available on several platforms and second, allow a screening of precipitation over the whole of the Mediterranean basin, including the sea, where in-situ observations are scarce, and where typically medicanes develop. This study builds on those of Funatsu et al. (2008, 2009), which investigated from a climatological point of view the mutual relationships between upper-level troughs and associated precipitation in the Mediterranean region using AMSU. Here we address the issue by looking at specific case studies, sometimes already described in the literature, but for which AMSU provides a complementary picture from studies based on reanalyses and ground station data. They were chosen in order to illustrate the variety of medicanes in terms of season, duration, trajectory (see Fig. 2), intensity. The first one appeared early in the morning of 26 September 2006 over the Ionian Sea and moved north-eastwards affecting southeast Italy, making possible a rather good observation of its characteristics. A maximum wind speed of around $39 \mathrm{~m} \mathrm{~s}^{-1}$ has been recorded at the Galatina Airport station, while a minimum sea level pressure of $986 \mathrm{hPa}$ was registered in the surroundings, which makes this case probably the deepest of the medicanes that have been registered so far. The study of this event benefited both from an observational (Moscatello et al., 2008a) and numerical studies (Moscatello et al., 2008b; Davolio et al., 2009). The second case which occurred in May 2003 affected the western Mediterranean Basin and was much weaker with maximum surface wind speeds of $13 \mathrm{~m} \mathrm{~s}^{-1}$. The third case, of intermediate intensity (maximum wind speed of $25 \mathrm{~m} \mathrm{~s}^{-1}$ ), developed in December 2005 near Tunisia and crossed practically the whole Mediterranean Basin from west to east, before decaying in Syria.

The paper is organized as follows. Section 2 describes AMSU data and the diagnostics used in this study to delineate the precipitation associated with medicanes and the mid- and upper-tropospheric environment in which they are embedded. Section 3 gives an overview of the three cases which have been considered. AMSU observations of these three cases are presented in the following Sect. 4. Finally, in Sect. 5, the results of the study are summarized and discussed. Possible implication of the use of AMSU for medicanes research and forecasting are highlighted.

\section{AMSU-based observations and diagnostics}

AMSU is a cross-scanning microwave instrument flying on board NOAA and MetOp polar-orbiting satellites since 1998. It consists of two modules (Table 1): AMSU-A which has channels in the molecular Oxygen frequencies (50-58 GHz), mainly designed for atmospheric temperature profiles retrieval (Fig. 3a), and AMSU-B (replaced by the 


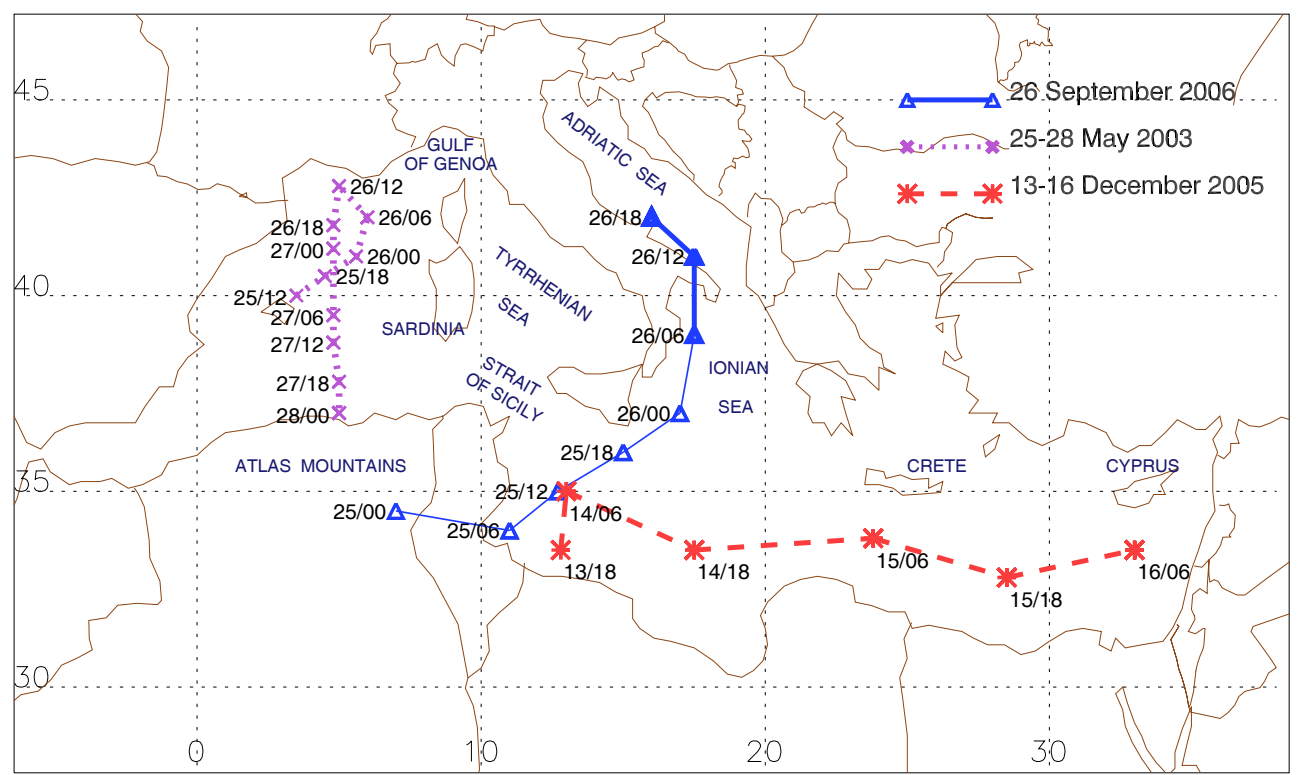

Fig. 2. Track of the three medicanes: (a) 26 September 2006 case (blue) as derived from ECMWF operational analyses every $6 \mathrm{~h}$ from 25 September 2006 at 00:00 UTC to 26 September 2006 at 18:00 UTC. The thick part of the line corresponds to the track of the medicane. (b) 25-28 May 2003 case (dotted purple) as derived from satellite imagery every $6 \mathrm{~h}$ from 25 May 12:00 UTC to 28 May 00:00 UTC (after Fita et al., 2007a). (c) 13-16 December 2005 case (dashed red) as derived from satellite imagery every 12 h from 13 December 18:00 UTC to 16 December 06:00 UTC (after Fita et al., 2007a; Luque et al., 2004).

Table 1. Frequencies and Band Width of AMSU-A and B channels.

\begin{tabular}{|c|c|c|}
\hline $\begin{array}{l}\text { Channel } \\
\text { Number }\end{array}$ & $\begin{array}{c}\text { Center Freq. } \\
(\mathrm{GHz})\end{array}$ & $\begin{array}{r}\text { Bandwidth } \\
(\mathrm{MHz})\end{array}$ \\
\hline \multicolumn{3}{|c|}{$A M S U-A$} \\
\hline 1 & 23.80 & 251 \\
\hline 2 & 31.40 & 161 \\
\hline 3 & 5.30 & 161 \\
\hline 4 & 52.80 & 380 \\
\hline 5 & $53.59 \pm 0.115$ & 168 \\
\hline 6 & 54.4 & 380 \\
\hline 7 & 54.94 & 380 \\
\hline 8 & 55.50 & 310 \\
\hline 9 & $57.29\left(f_{0}\right)$ & 310 \\
\hline 10 & $f_{0} \pm 0.217$ & 76 \\
\hline 11 & $f_{0} \pm 0.320 \pm 0.048$ & 34 \\
\hline 12 & $f_{0} \pm 0.322 \pm 0.022$ & 15 \\
\hline 13 & $f_{0} \pm 0.322 \pm 0.010$ & 8 \\
\hline 14 & $f_{0} \pm 0.322 \pm 0.004$ & 3 \\
\hline 15 & 89.00 & 2000 \\
\hline \multicolumn{3}{|c|}{$A M S U-B^{*}$} \\
\hline 1 & 89 & 5000 \\
\hline 2 & 150 & 4000 \\
\hline 3 & $183 \pm 1$ & 1000 \\
\hline 4 & $183 \pm 3$ & 2000 \\
\hline 5 & $183 \pm 7$ & 4000 \\
\hline
\end{tabular}

* On MHS, the center frequency for Channels 2 and 5 is 157 and $190 \mathrm{GHz}$, respectively.
Microwave Humidity Sounder, or MHS, on recent platforms; Fig. 3b) which has three channels centered in a water vapour absorption line (183-191 GHz), designed for optimal moisture retrieval. Furthermore, both modules have window channels, which are not used in this study. The nearnadir instantaneous field of view of AMSU-A and AMSU$\mathrm{B} / \mathrm{MHS}$ is of $48 \mathrm{~km}$ and $16 \mathrm{~km}$, respectively, and both have a swath width of approximately $2300 \mathrm{~km}$. Further details on the instruments can be found in the NOAA's KLM User's Guide available online at http://www2.ncdc.noaa.gov/docs/ $\mathrm{klm} /$. Table 2 provides a summary of the platforms that carry the AMSU instruments. Because of the different equatorial crossing times (and in spite of the drift of some satellites), this configuration offers a rather good temporal sampling of any region in the world and therefore of the Mediterranean Basin, as will be illustrated below.

Due to the fact that a thicker layer of the atmosphere is probed as the field of view departs from the nadir position, AMSU-A data was corrected for limb effect using coefficients derived from the Radiative Transfer for TOVS (RTTOV, Saunders et al., 2005), following the correction procedure described in Funatsu et al. (2007 . The data was then re-sampled to a regular $1^{\circ} \times 1^{\circ}$ lat/lon grid, using a smoothing criterion of $1-\left(r / r_{\mathrm{d}}\right)^{2}$, where $\mathrm{r}$ is the distance of the actual data point to the fixed grid point, and $r_{\mathrm{d}}$ is the radius of search (fixed to $2.5^{\circ}$ ). For AMSU-B/MHS, the brightness temperature (BT) data was re-sampled without smoothing to a regular grid of $0.2^{\circ} \times 0.2^{\circ}$, using a weighting of $1 / r^{2}$. Consecutive satellite passes covering the domain of $10^{\circ}-60^{\circ} \mathrm{N}$, 
Table 2. List of platforms carrying AMSU radiometers and major characteristics: launch dates, status of AMSU-B/MHS channels and AMSU-A channels 5, 7, 8. LTAN is for Local Time Ascending Node. The value is given at the time of the launching of the satellite. Due to orbital drifts, LTAN in May 2010 is 16:41, 18:25, and 21:04 for NOAA-15, NOAA-16, NOAA-17, respectively.

\begin{tabular}{llrrl}
\hline Platform & Radiometer & Launch date & LTAN & Operational status \\
\hline NOAA-15 & AMSU-A/B & 13 May 1998 & $19: 20$ & \\
NOAA-16 & AMSU-A/B & 21 Sep 2000 & $14: 24$ & \\
NOAA-17 & AMSU-A/B & 24 Jun 2002 & $22: 25$ & Channels A-5, 7, and 8 off since 30 Oct 2003 and \\
& & & & B-3, 4, and 5 off since 13 Jan 2010 \\
NOAA-18 & AMSU-A/MHS & 20 May 2005 & $13: 41$ & \\
MetOp-2 & AMSU-A/MHS & 19 Oct 2006 & $21: 30$ & operational after May 2007 Channel 7 failed since 6 Dec 2009 \\
NOAA-19 & AMSU-A/MHS & 6 Feb 2009 & $13: 43$ & \\
\hline
\end{tabular}
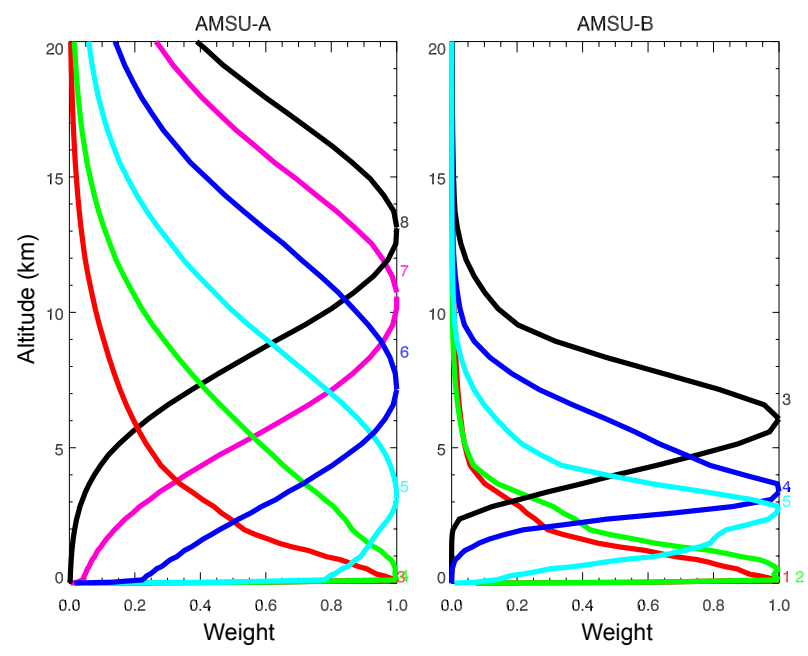

Fig. 3. Normalized weighting functions for (a) the AMSU-A temperature channels sounding in the troposphere (3-8) and (b) AMSU-B channels at nadir, for a Mediterranean atmospheric profile. Note that Channels 2 and 5 differ between AMSU-B and MHS, but their weighting function is very close, so that only AMSU-B weighting functions are shown.

$10^{\circ} \mathrm{W}-50^{\circ} \mathrm{E}$ were concatenated in their descending and ascending motions providing, for each satellite, twice daily BT information for this area.

\subsection{Mid-tropospheric temperature and upper-level troughs}

Among the AMSU channels which sound the troposphere, AMSU-A channel 5 (hereafter, A-5) with a weighting function that maximizes near $3.5 \mathrm{~km}$ (Fig. 3a), can be used to describe the temperature in the mid-troposphere.

Funatsu et al. (2007) have shown that in the Mediterranean, AMSU-A channel 8 (hereafter, A-8) that has a weighting function with a peak near $200 \mathrm{hPa}$ can be used for detection of upper-level troughs frequently observed in the vicinity of heavy precipitating systems. Warm A-8 ar- eas were found to be near coincident with areas of high potential vorticity $(\mathrm{PV})$ in the upper-troposphere, indicating the presence of air of stratospheric origin. Unlike PV which is a conservative quantity, there is not a single BT threshold to characterize these dynamical systems: a A-8 BT of at least $221 \mathrm{~K}$ was nevertheless shown to be necessary to identify a PV value greater than 4 PVU $(1 \mathrm{PVU}=1.0 \times$ $10^{-6} \mathrm{~m}^{2} \mathrm{~s}^{-1} \mathrm{~K} \mathrm{~kg}^{-1}$ ) at $250 \mathrm{hPa}$ (Funatsu et al., 2007, 2008).

Another diagnostic parameter is given by the BT differences of Channels 7 and 5 (hereafter A7m5). This combination of channels provides information on the downward penetration of the upper-level trough, a less negative value representing a deeper vertical penetration (Funatsu et al., 2007).

\subsection{Moderate rain and deep convection}

AMSU-B/MHS moisture channels (3-5) detect the presence of hydrometeors through the scattering of radiation which lowers the brightness temperature compared to its surroundings (Greenwald and Christopher, 2002). Based on this property, Funatsu et al. (2007) showed that a combination of Channels 3 and 5 of AMSU-B can detect precipitating areas; a BT difference of Channels 3 minus 5 (hereafter, B3m5) equal or larger than $-8 \mathrm{~K}$ was found to correspond statistically to a rainfall of at least $10 \mathrm{~mm}$ in $3 \mathrm{~h}$ when compared to the Tropical Rainfall Measuring Mission (TRMM) 3B42 3-hourly accumulated precipitation product. Areas of deep convection are detected using a criterion initially devised to identify convection in the tropical regions (Hong et al., 2005), called the "deep convective threshold" (DCT). It is defined such that B3m5, B4m5 and B3m4 (i.e., AMSU-B/MHS channels 4 minus 5 , and 3 minus 4 , respectively) are simultaneously equal or larger than zero. When compared with TRMM data, DCT was found to correspond in the Mediterranean region to an accumulated rainfall of at least $20 \mathrm{~mm}$ in $3 \mathrm{~h}$ in $50 \%$ of the cases. Both thresholds were validated for rain detection in the Mediterranean over surfaces free of snow or ice (Funatsu et al., 2007) with radar and rain gauges from meteorological ground stations for selected heavy precipitating events. 


\section{Case studies}

A short description of the three case studies is now given; because the September 2006 case benefited from a larger number of observations resulting in more in-depth studies (see below) than the other two, it is presented at length.

\subsection{The 26 September 2006 case}

This case (see trajectory on Fig. 2) was rather unusual in that the inland movement of the cyclone made a rather good observation of its characteristics possible (the area affected by the cyclone was covered by two radars and a high resolution surface station network; Moscatello et al., 2008a). A deeper understanding of the event was obtained from numerical simulations and sensitivity studies (Moscatello et al., 2008b; Davolio et al., 2009). The overview of the case given below is based on these three studies.

The mesoscale system originated during the night between 24 and 25 September on the lee side of the Algerian Atlas Mountains as an orographic cyclone (Fig. 2). Favourable conditions were further created by a baroclinic system deepening over the Tyrrhenian Sea (see also Fig. 6). On 25 September at 06:00 UTC, the low reached the Strait of Sicily, where it deepened due to convection produced along a cold front moving eastward. At that time the relatively large orographically generated cyclone became a much smaller-scale vortex. The vortex subsequently moved northeastwards and on 26 September at 00:00 UTC, the low entered the Ionian Sea where it further deepened by more than $10 \mathrm{hPa}$ in $6 \mathrm{~h}$. At about 09:00 UTC, the now medicane entered the Adriatic Sea (Fig. 1a), where both surface fluxes and latent heat release sustained its intensity. Wind speed measured at Galatina airport $\left(40.2^{\circ} \mathrm{N}, 18.1^{\circ} \mathrm{E}\right)$ recorded a maximum speed of $78 \mathrm{kt}$, and several surface stations recorded a sharp decrease of the mslp (mean sea level pressure), down to $986 \mathrm{hPa}$. Based on satellite images and ground observations, the diameter of the vortex eye was estimated at about $60 \mathrm{~km}$. Later in the day, the medicane moved over the Adriatic Sea, following an arc-shape trajectory, and was still associated with low values of mslp. At 17:00 UTC, the cyclone made landfall, and weakened rapidly to finally merge with the other low pressure system, still located over the Tyrrhenian Sea.

Note that the reflectivity maps from the radar located at $40^{\circ} \mathrm{N}, 18^{\circ} \mathrm{E}$ valid for 26 September at about 09:00 UTC clearly revealed the absence of precipitation near the mslp minimum (the eye of the cyclone), and a circle of precipitation around it. Maximum values of about $24 \mathrm{~mm} \mathrm{~h}^{-1}$ were recorded by the radar during the passage of the medicane and a maximum of $120 \mathrm{~mm}$ was observed at the station Crispiano $\left(40.6^{\circ} \mathrm{N}, 17.4^{\circ} \mathrm{E}\right)$ during the transit of the medicane over the area (Moscatello et al., 2008a).

\subsection{The 25-28 May 2003 case}

This case formed on 25 May 12:00 UTC and lasted through 28 May 04:30 UTC (Fita et al., 2007a). It developed in Gulf of Lyon and after a quasi-stationary phase, it traveled southward (Fig. 2). An eye could be observed over the time period 08:30-15:30 UTC 27 May (Fig. 1b). The maximum wind speed was estimated to $13 \mathrm{~m} \mathrm{~s}^{-1}$ (Fita et al., 2007a).

\subsection{The 13-16 December 2005 case}

According to Fita et al. (2007a), this case lasted from 13 December 05:00 UTC until 16 December 12:00 UTC. The medicane formed south of Sicily (Fig. 1c), remained more or less stationary until 14 December 16:00 UTC (Luque et al., 2007), and then crossed the whole Mediterranean (Fig. 2). It developed an eye twice, first on 14 December between 08:00 and 15:00 UTC, and then, on 15 December, between 06:00 and 14:00 UTC. According to Fita et al. (2007a), it achieved a minimum mslp of $991 \mathrm{hPa}$ on 14 December at 06:00 UTC, with a surface wind speed of $25 \mathrm{~m} \mathrm{~s}^{-1}$ and then of $993.5 \mathrm{hPa}$ on 15 December at 12:00 UTC. From satellite imagery, its radius could be estimated from 100 to $140 \mathrm{~km}$.

\section{AMSU observations of the medicanes}

As already mentioned, we will focus on the rather wellobserved September 2006 case and then show the validity of the observations made for this case for the other two cases: in spite of different features for rain and convection, convection onset is always related to a similar synoptic setting. Although moderate and deep convective rain are shown for the entire area, only the features associated with the medicanes are discussed below. Fields of AMSU-A7m5 are not shown, because they show a lot of similarities with A-8 but they are discussed.

\subsection{The 26 September 2006 case}

For this case, NOAA-15, NOAA-16 and NOAA-18 data are available, offering a good temporal sampling with 6 passes on 26 September between 01:00 UTC and 14:00 UTC, i.e. the time period during which this system was a medicane.

The synoptic conditions leading to this development are first described using consecutive NOAA-16 observations from 19 to 25 September (Fig. 4). An upper-level trough formed as early as during the night from 19 to 20 September over the Atlantic Ocean (Fig. 4a). The trough intensified and moved south-eastwards extremely rapidly as can be seen on the following passes (Fig. 4b-e). From 24 to 25 September, the orientation of the trough changed from North-South (N-S) to Northwest-Southeast (NW-SE), and narrowed. Late on the 25th, large values of A-8 were present over the western Mediterranean (Fig. 4g), just upstream of the low situated at 12:00 UTC south of the Strait 
(a) N16 22-03UTC 20 Sep 2006

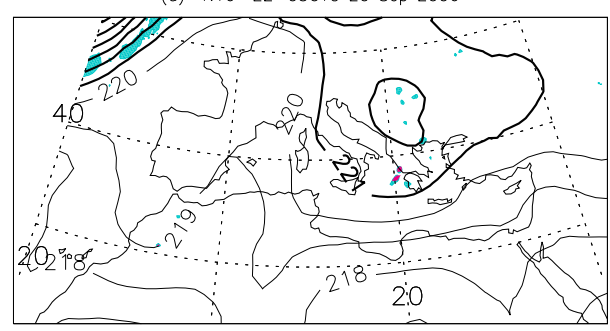

(c) N16 22-03UTC 22 Sep 2006

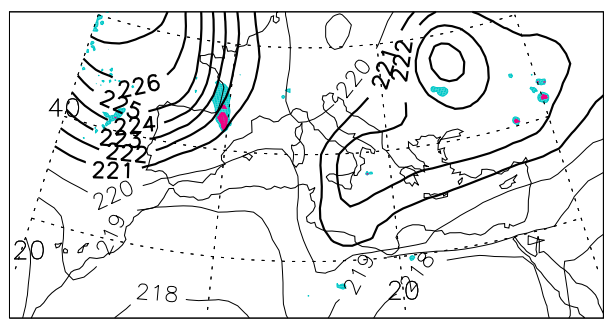

(e) N16 22-03UTC 24 Sep 2006

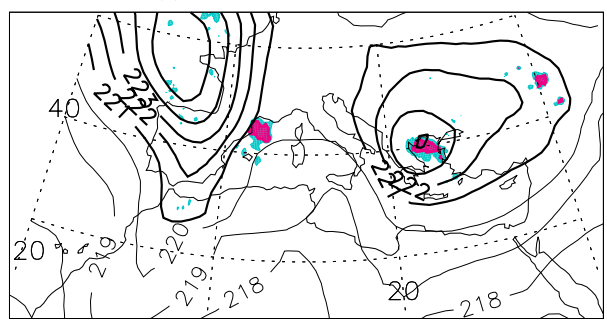

(g) N16 08-13UTC 25 Sep 2006

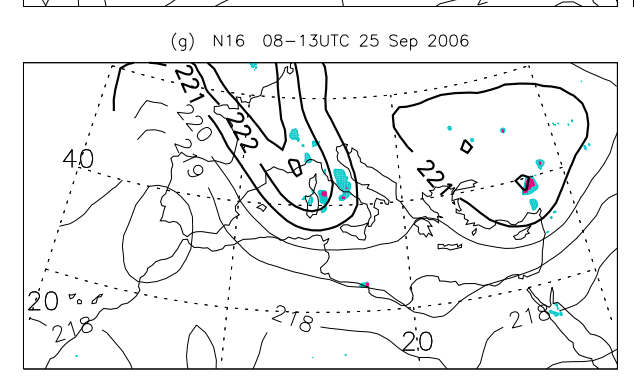

(b) $\mathrm{N} 16 \quad 22-03$ UTC 21 Sep 2006

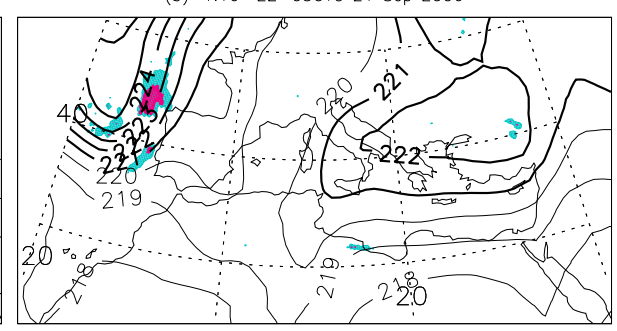

(d) N16 22-03UTC 23 Sep 2006

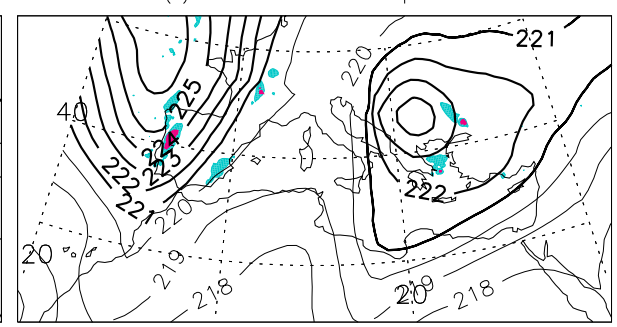

(f) N16 22-03UTC 25 Sep 2006

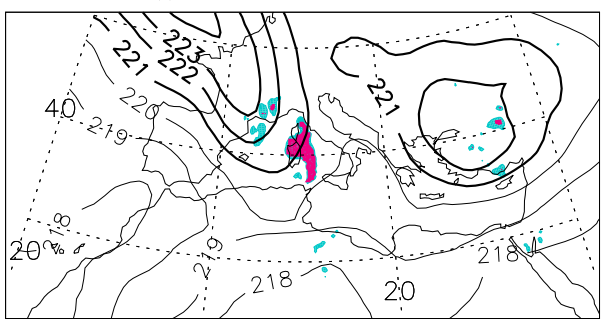

Fig. 4. AMSU-A channel 8 (solid, thick dark for A-8 BT larger or equal to $221 \mathrm{~K}$ ), B3m5 (larger or equal to $-8 \mathrm{~K}$, blue shaded), and DCT (red shaded) for (a-f), descending (22:00-03:00 UTC) and (g), ascending (08:00-13:00 UTC), NOAA-16 passes, 20-25 September 2006.

of Sicily, and the edge of the trough took a slight zonal (cyclonic) orientation. Fields of AMSU-A7m5 also show that the depth of the intrusion increases with time, with a maximum value of $-25 \mathrm{~K}$ reached on the evening of the 25 th (not shown). At that time, an outbreak of very cold air is observed in mid-tropospheric temperatures, leading to a rather strong gradient south of Sardinia (Fig. 5). As already noted by Funatsu et al. (2007), there is a fair agreement between A-8 and ECMWF (European Centre for MediumRange Weather Forecasts) PV fields at $250 \mathrm{hPa}$ (Fig. 6) all along this period.

Advantage is now taken of the time coverage differences between the platforms that carry AMSU to give a very complete temporal description of the disturbance, especially in terms of convection and precipitation areas (Fig. 7).

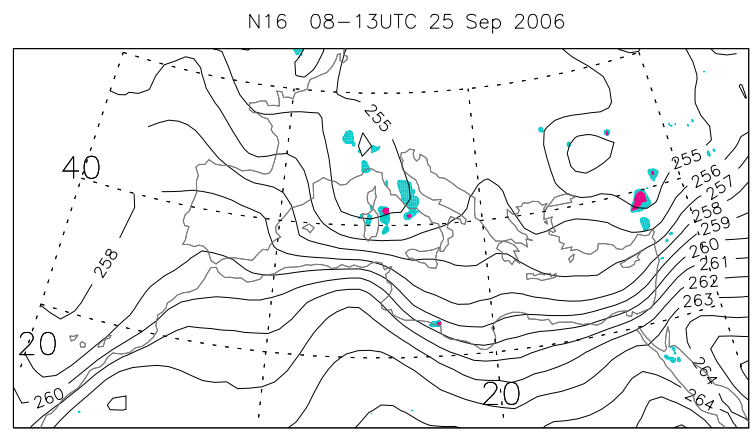

Fig. 5. AMSU-A channel 5 (in $\mathrm{K}$ ), B3m5 (larger or equal to $-8 \mathrm{~K}$, blue shaded), and DCT (red shaded) for ascending (08:0013:00 UTC) NOAA-16 passes, 25 September 2006. Isolines are displayed every $\mathrm{K}$. 

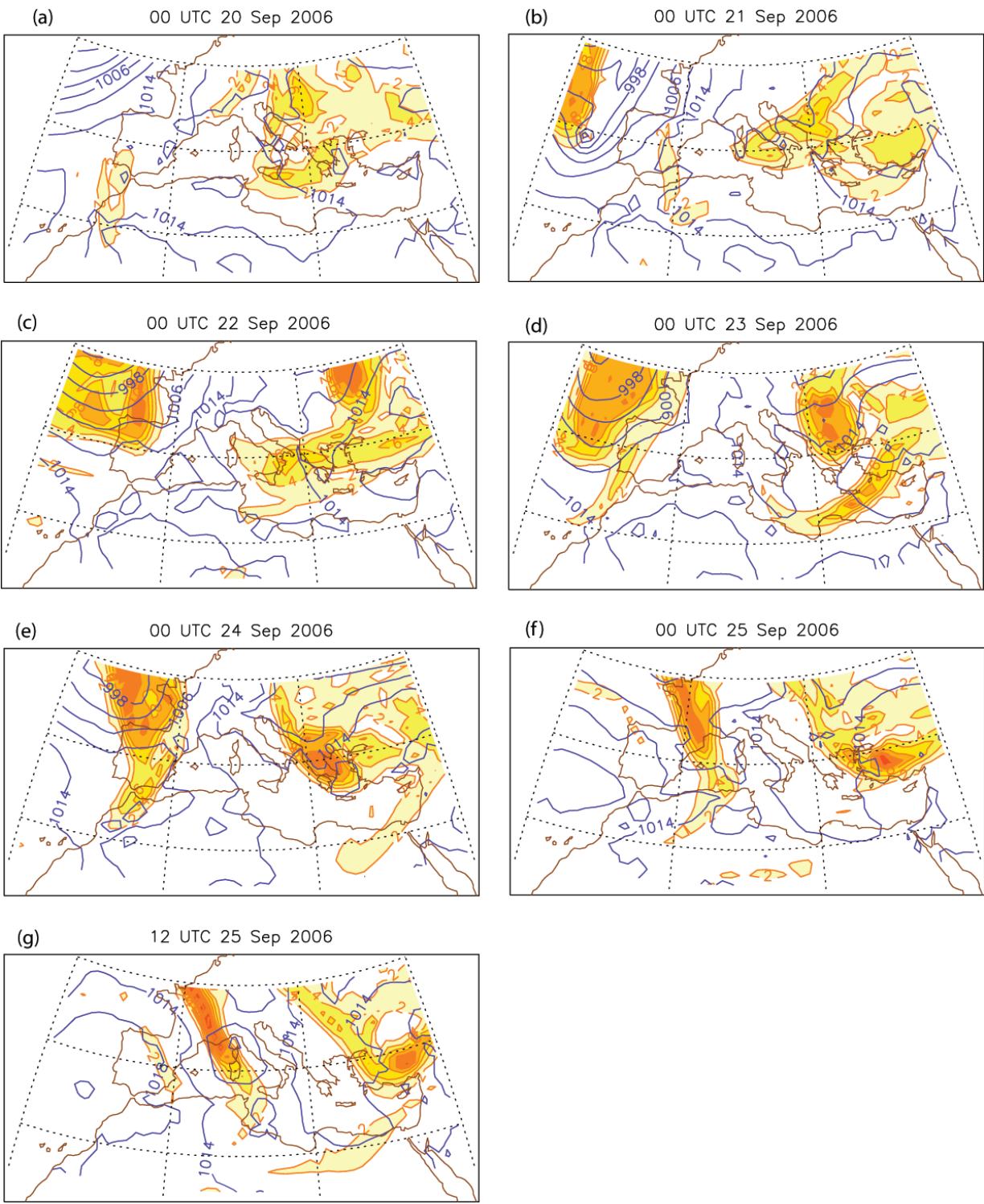

Fig. 6. ECMWF operational mean sea level pressure (in hPa, every $4 \mathrm{hPa}$ ) and potential vorticity (in PV Units; $1 \mathrm{PVU}^{\mathrm{P}}=10^{-6} \mathrm{~K} \mathrm{~m}^{2} \mathrm{~kg}^{-1} \mathrm{~s}^{-1}$ ) at $250 \mathrm{hPa}$ for the period from 20 September 2006 until 25 September 2006, 12:00 UTC.

A combination of AMSU-B/MHS observations permit to investigate precipitation associated with the system while coincident AMSU A-5 observations give insights into the larger synoptic-scale environment in which it occurs.

At 01:00 UTC, MHS observations reveal that deep convection occurs in three large cells, the southernmost one corresponding to the medicane (Fig. 7a). According to AMSU, this was the time when convection was the most important spatially ; however MHS might be slightly more sensitive than AMSU-B to convection (Mo, 2006), and this may have contributed to this result. Convection remains sustained during the next hours in the north-eastern part of the cyclone (Fig. 7b-c), and rainfall widespread. While at 11:00 UTC (Fig. 7d), precipitation and to a lesser extent convection are observed over a rather large area, it is much more localized at 14:00 UTC (Fig. 7e) and at 16:00 UTC (Fig. 7f). Note that there is a fair agreement between AMSU-derived rain fields and the reflectivity maps from the radar in Bari Balese presented in Fig. 8 of Moscatello et al. (2008a) (even if, as expected from the spatial resolution of AMSU-B/MHS, the fine-scale structures of the reflectivity fields are lacking).

The concomitant evolution of A-8 and A-5 on Fig. 7a shows the typical configuration at the time of convection onset: cold air in the mid-troposphere with an area of warm A-8 upstream. Interestingly, as time passes, the area of warm A-8 values moves south-eastward and remains close to or above the surface low, but with reduced A- 8 and $\mathrm{A} 7 \mathrm{~m} 5$ values. This configuration is confirmed by ECMWF fields (PV at $250 \mathrm{hPa}$ and $1000-500 \mathrm{hPa}$ geopotential thicknesses) for 26 September at 00:00, 06:00, and 12:00 UTC (Fig. 8). 

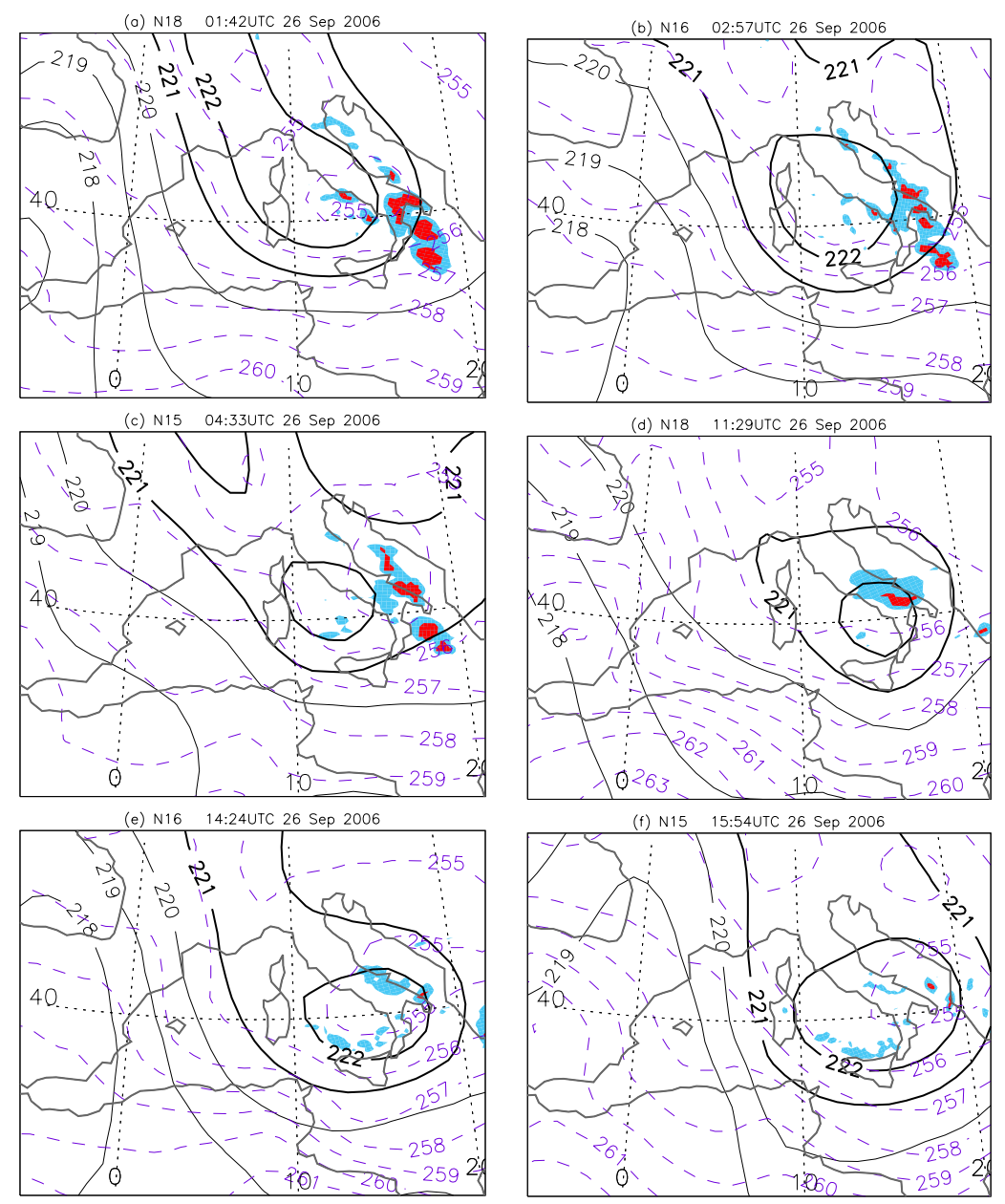

Fig. 7. AMSU-A channel 8 (solid, thick dark for A-8 BT larger or equal to $221 \mathrm{~K}$ ), AMSU-A channel 5 (dashed, purple), B3m5 (larger or equal to $-8 \mathrm{~K}$, blue shaded), and DCT (red shaded), for: (a) NOAA-18, 01:42 UTC, (b) NOAA-16, 02:57 UTC, (c) NOAA-15, 04:33 UTC, (d) NOAA-18, 11:29 UTC, (e) NOAA-16, 14:24 UTC, (f) NOAA-15, 15:54 UTC.
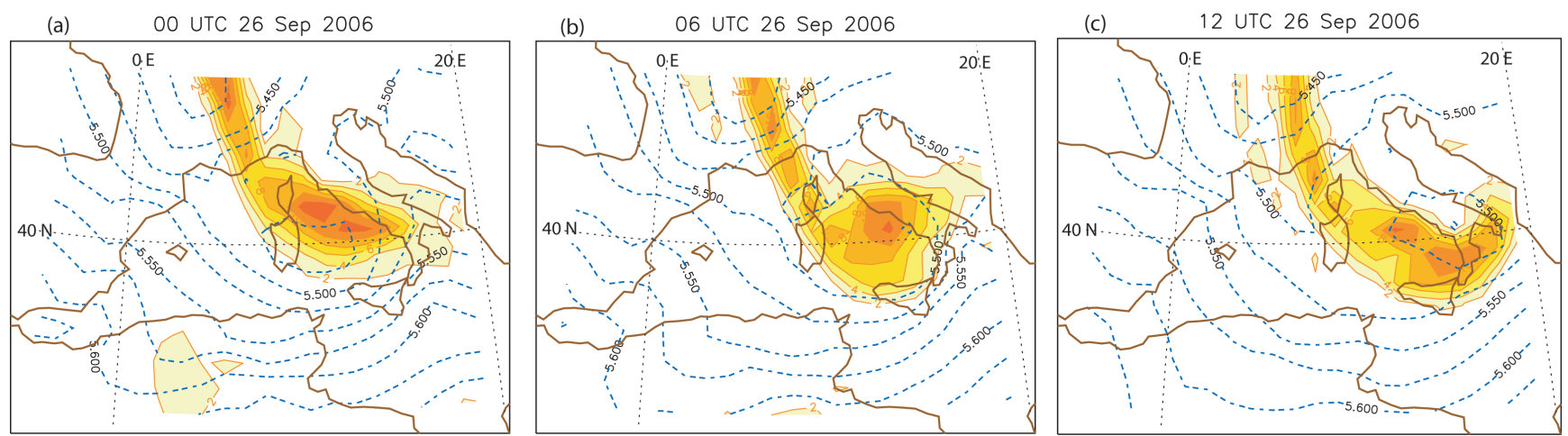

Fig. 8. ECMWF operational $1000-500 \mathrm{hPa}$ geopotential thicknesses (in $10^{4} \mathrm{~m}^{2} / \mathrm{s}^{2}$ ) and potential vorticity at $250 \mathrm{hPa}$ (in PV Units) for 26 September 2006 at (a) 00:00 UTC, (b) 06:00 UTC, and (c) 12:00 UTC.

\subsection{The 25-28 May 2003 case}

NOAA-15, NOAA-16 and NOAA-17 data are available for this case, again offering a good temporal sampling of the storm and its environment.
Figure 9 displays AMSU-A channel 8 for the period 2325 May. It clearly shows the formation of an upper-level trough during 23 May over the Atlantic Ocean (Fig. 9a). As its amplitude increases, it follows a south-eastward 
(a) N16 22-05UTC 23 May 2003

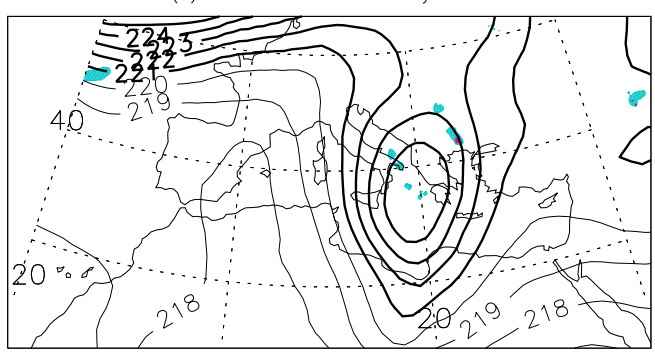

(c) N16 22-05UTC 24 May 2003

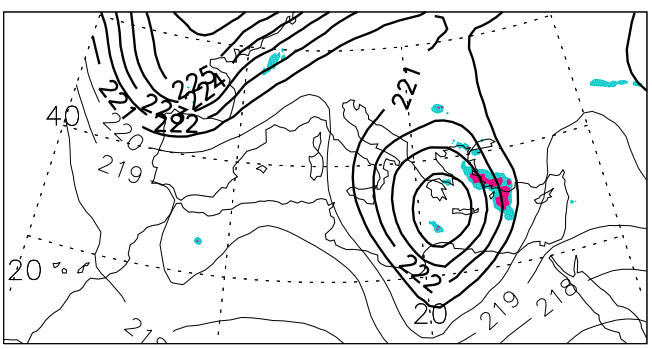

(e) N16 22-05UTC 25 May 2003

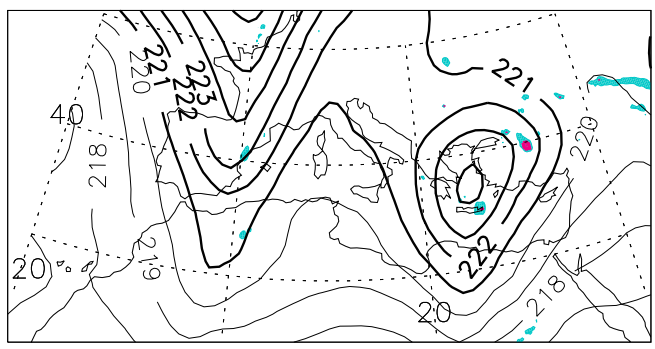

(b) N16 08-15UTC 23 May 2003

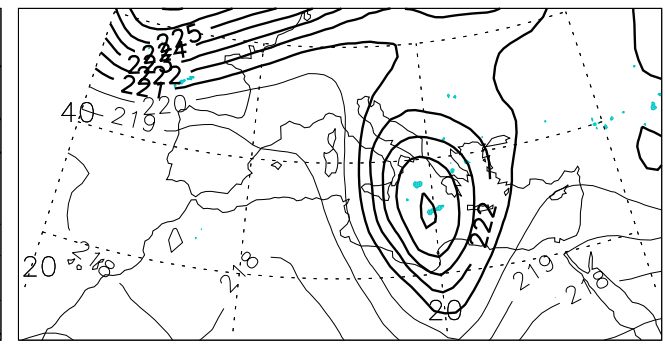

(d) N16 08-15UTC 24 May 2003

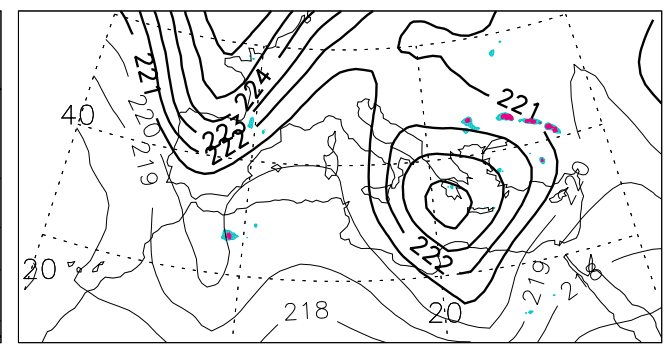

(f) N16 08-15UTC 25 May 2003

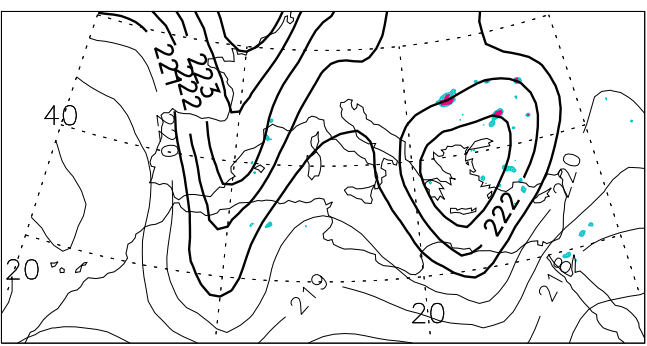

Fig. 9. Same as Fig. 4 but for 23-25 May 2003, (a, c, e) descending (22:00-03:00 UTC), and (b, d, f) ascending (08:00-13:00 UTC).

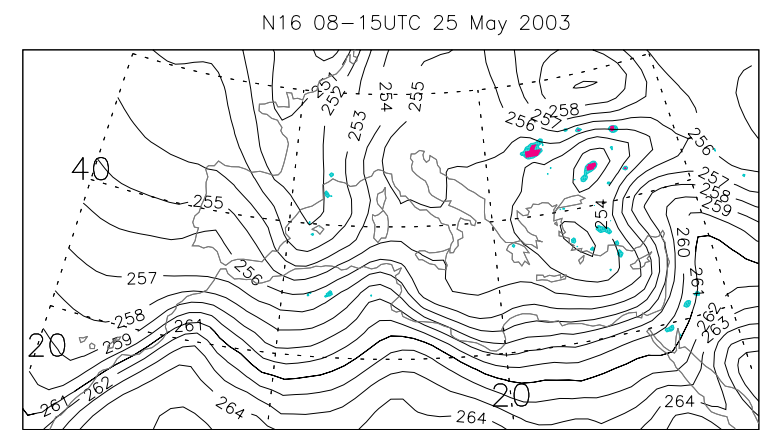

Fig. 10. Same as Fig. 5, but for 25 May 2003, 08:00-15:00 UTC.

movement. Late on 25 May, its orientation that was N$\mathrm{S}$ becomes slightly NW-SE (Fig. 9f). It is also shown at that time that the trough has reached in maximum amplitude and depth: fields of AMSU-A7m5 (qualitatively very similar to A-8) show a maximum value of $-22 \mathrm{~K}$ over a small area extending from the Balearic Islands towards the French-Spanish coast (not shown). Concomitant with this, AMSU A-5 fields show a cold air outbreak over the Gulf of Lyon, which creates a strong gradient more to the south, over Northern Africa (Fig. 10).
This situation precedes the onset of precipitation, which is maximal in the evening and during the night of 25 to 26 May (Fig. 11). In terms of spatial extent, the maximum is reached on 26 May at 03:00 UTC (Fig. 11c), where the configuration in terms of A-8 and A-5 is close to the one depicted in Fig. 7a for the September 2006 medicane. DCT areas are rather marginal for this case that was rather weak (maximum wind speed of $13 \mathrm{~m} \mathrm{~s}^{-1}$ ), in spite of the impressive structure seen on satellite imagery (Fig. 1b). After this phase (Fig. 11d-h), the medicane follows a southward trajectory but no DCT is detected and moderate rain is significantly reduced. This is the time when an eye formed (Fig. 1b). As for the preceding case, the trough, which is no longer upstream of the surface low and thus not in a configuration where it can interact with the medicane, and with an amplitude and depth that decrease progressively, also follows the same trajectory.

\subsection{The 13-16 December 2005 case}

As for the 26 September case, NOAA-15, NOAA-16 and NOAA-18 data are available for this case, which lasted about $80 \mathrm{~h}$ and travelled from Tunisia to Syria. 

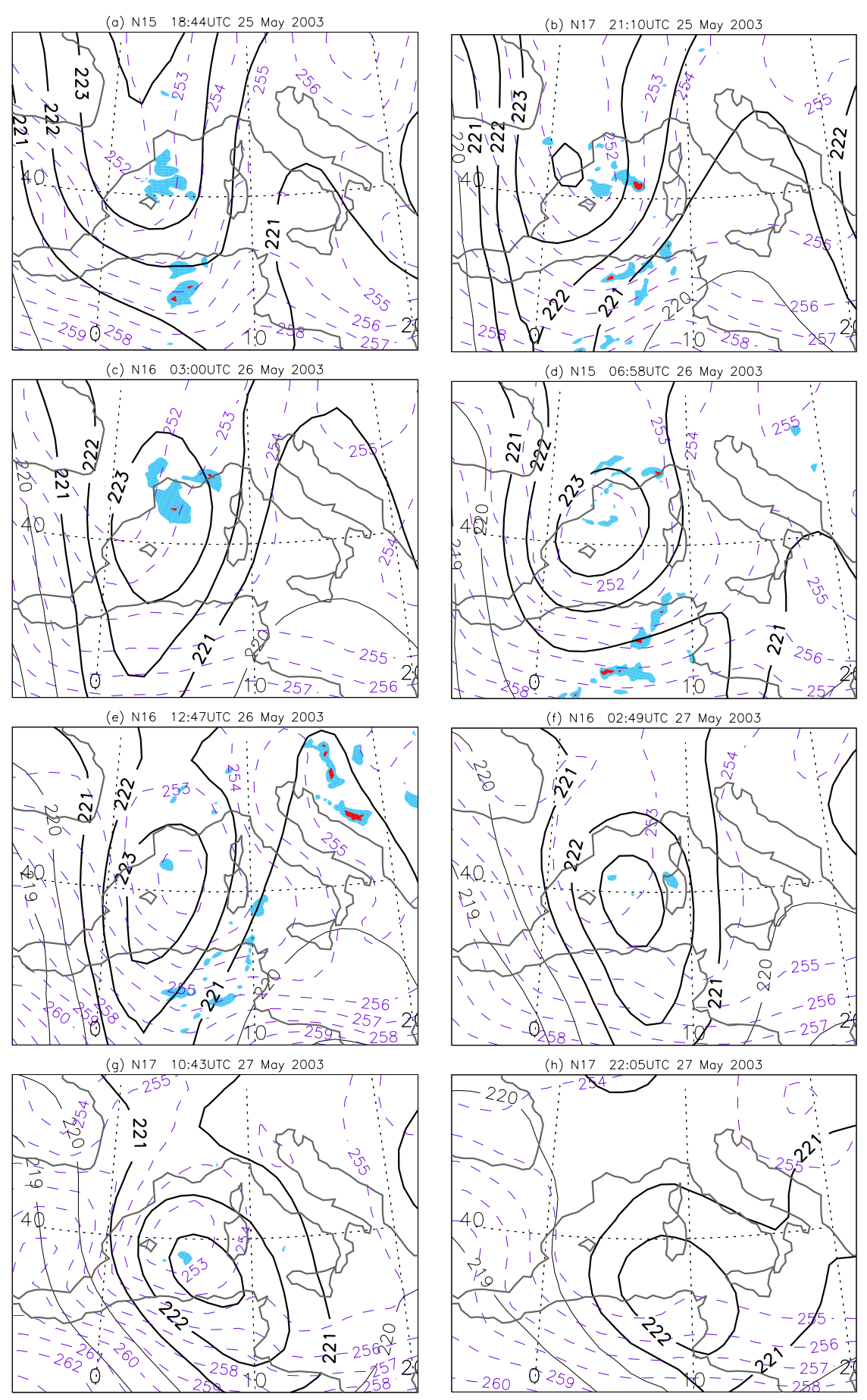

Fig. 11. Same as Fig. 7, but for: (a) NOAA-15, 25 May 2003, 18:44 UTC, (b) NOAA-17, 25 May 2003, 21:10 UTC, (c) NOAA-16, 26 May 2003, 03:00 UTC, (d) NOAA-15, 26 May 2003, 06:58 UTC, (e) NOAA-16, 26 May 2003, 12:47 UTC, (f) NOAA-16, 27 May 2003, 02:49 UTC, (g) NOAA-17, 27 May 2003, 10:43 UTC, (h) NOAA-17, 27 May 2003, 22:05 UTC.

For this medicane, the A- 8 warm structures formed between 9 and 10 December (Fig. 12a-b) and intensified on-site (Fig. 12c-d), with the shape changing during 12 December. Fields of AMSU-A7m5 indicate that the depth of the intru- sion has increased to a maximum value of $-21 \mathrm{~K}$ reached during this day (not shown). The A-5 field depicts an area of extremely cold air over Western Europe with a sharp gradient bounding it (Fig. 13). 
(a) 22-05UTC 09 Dec 2005

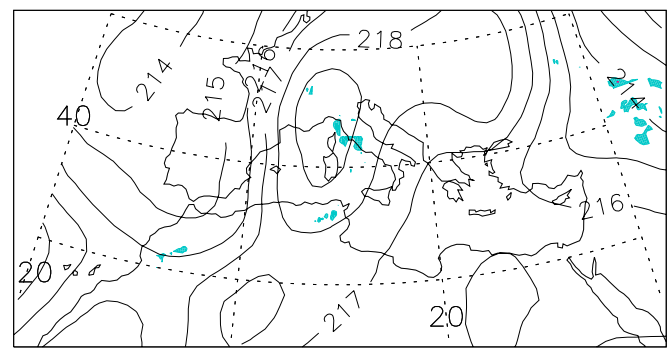

(c) 22-05UTC 11 Dec 2005

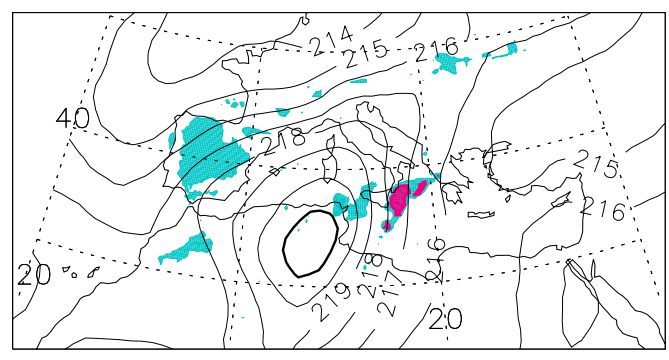

(e) 08-15UTC 12 Dec 2005

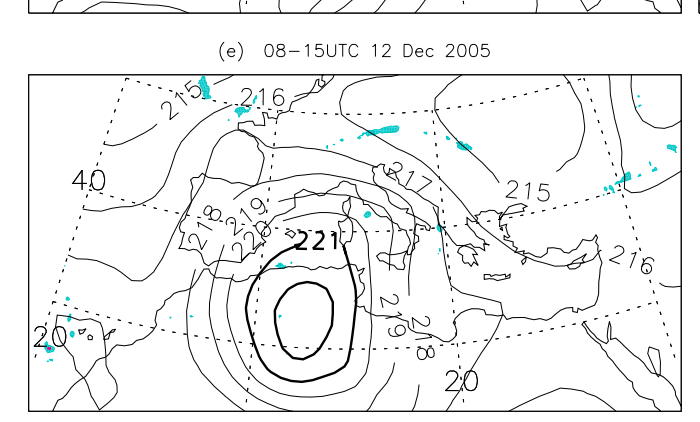

(b) 22-05UTC 10 Dec 2005

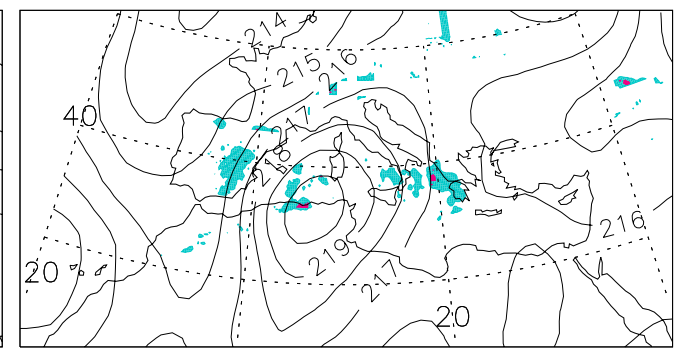

(d) 22-05UTC 12 Dec 2005

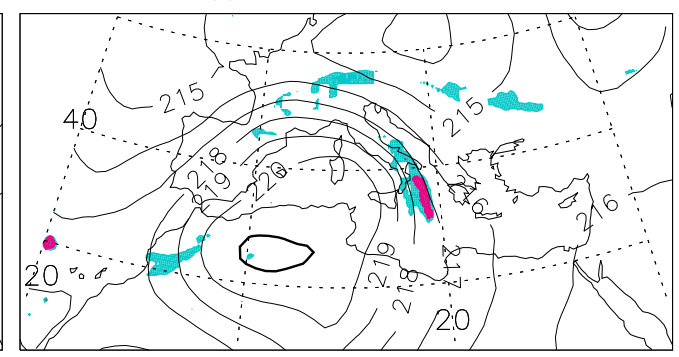

Fig. 12. Same as Fig. 4, but for 9-12 December 2005, (a-d), descending (22:00-03:00 UTC), and (e), ascending (08:00-13:00 UTC).

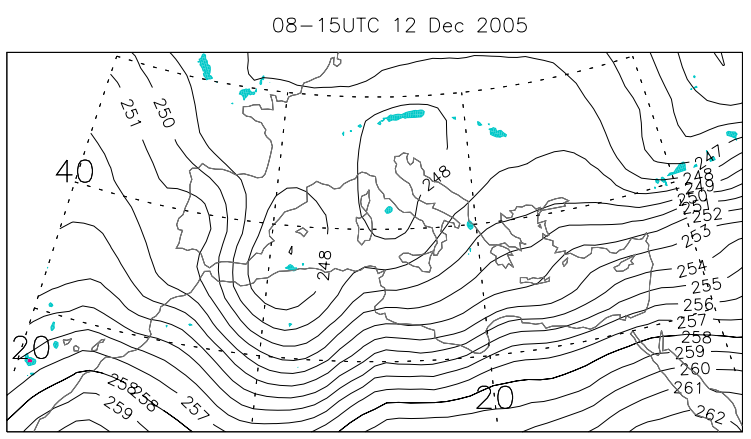

Fig. 13. Same as Fig. 5, but for 12 December 2005, 08:0015:00 UTC.

The medicane, that formed early on 13 December near Tunisia, was at that time characterized by a rather extended area of deep convection and rain, just ahead of the $221 \mathrm{~K}$ A-8 isoline (Fig. 14). Convection and rain remained sustained during the morning (Fig. 14a-b), but afterwards, rain and convection (Fig. 14c-j) were reduced. A small re- intensification of the upper-level structure occurred at around mid-day on 14 December (Fig. 14e-f), that was followed by a bit more rain and convection, compared to the preceding stage. The intensity of the warm A- 8 anomaly then decreased and the anomaly travelled eastward, before vanishing on 16 December (Fig. 14h-j). Unlike the two previous cases, the medicane was more baroclinic in nature, as observed on A-5 fields which display a strong gradient in the medicane area. Note however that in the incipient stage (Fig. 14a-b), rain and convection associated with the medicane occur in an area of cold air (A-5 between 249 and $251 \mathrm{~K})$.

\section{Summary and conclusions}

Subsynoptic-scale vortices that have been likened to tropical cyclones or polar lows (medicanes) are occasionally observed over the Mediterranean Sea (about 30 cases during the last 25 years; http://www.uib.es/depart/dfs/meteorologia/ METEOROLOGIA/MEDICANES/). Because they are generally associated with strong winds and heavy precipitation 

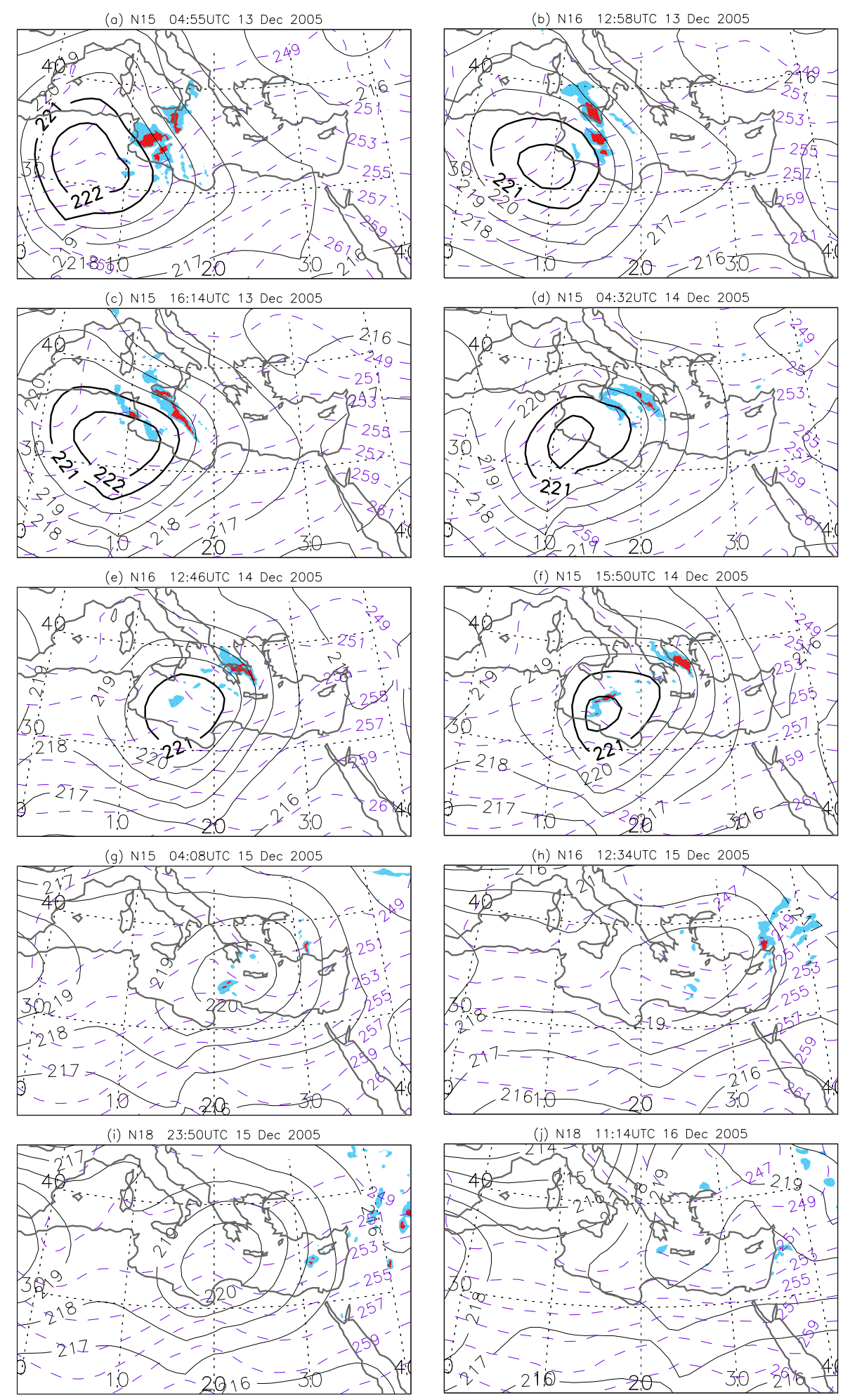

Fig. 14. Same as Fig. 7, but for: (a) NOAA-15, 13 December 2005, 04:55 UTC, (b) NOAA-16, 13 December 2005, 12:58 UTC, (c) NOAA-15, 13 December 2005, 16:14 UTC, (d) NOAA-15, 14 December 2005, 04:32 UTC, (e) NOAA-16, 14 December 2005, 12:46 UTC, (f) NOAA-15, 14 December 2005, 15:50 UTC, (g) NOAA-15, 15 December 2005, 04:08 UTC, (h) NOAA-16, 15 December 2005, 12:34 UTC, (i) NOAA-18, 15 December 2005, 23:50 UTC, (j) NOAA-18, 16 December 2005, 11:14 UTC. Note that A-5 isolines are displayed every $2 \mathrm{~K}$. 
and because their occurrence may increase under future climate change conditions (Gaertner et al., 2007), an improved knowledge of the conditions in which they develop is essential. It could lead to an improvement of their forecast and thus mitigate their potentially highly destructive effects in densely populated regions.

Three medicanes have been investigated in this study. One appeared early in the morning of 26 September 2006 over the Ionian Sea and moved north-eastwards affecting southeast Italy; with a maximum wind speed of around $39 \mathrm{~m} \mathrm{~s}^{-1}$ and a minimum sea level pressure of $986 \mathrm{hPa}$, this case was probably the deepest of the medicanes ever registered. The second case occurred in May 2003, affected the western Mediterranean Basin from north to south and was much weaker with maximum surface wind speeds of $13 \mathrm{~m} \mathrm{~s}^{-1}$. The third case, of intermediate intensity (maximum wind speed of $25 \mathrm{~m} \mathrm{~s}^{-1}$ ), developed in December 2005 near Tunisia and crossed practically the whole Mediterranean Basin from west to east. The last two medicanes, of low and moderate intensity, were not represented in operational analyses. As already noted in the literature, these three cases illustrate the large variability in medicanes characteristics: season, duration, trajectory, and intensity.

Our study is based exclusively on new-generation microwave satellite sensors that permit a concomitant observation of convection/ precipitation associated with medicanes and their embedded large-scale environment, at a temporal resolution higher that that of meteorological analyses (because these sensors are flown on several platforms).

Considering the three above-cases, satellite microwave observations show that:

1. Convection and extended rain onset occur when an upper-level trough, that formed a few days earlier, is just upstream of a cold air area in the mid-troposphere, and whenever the maximum amplitude and depth have been reached and a cyclonic curvature has been taken by the trough.

2. Precipitation is important in this early phase of the medicane and then significantly reduced, especially during the itinerant phase (Luque et al., 2004). For the case in 2003 and to a lesser extent the one in 2005, there was practically no rain after the time the eye formed in spite of the rather impressive cloud structure seen on satellite imagery. Spatially, the extent of deep convection and rain varies a lot from case to case, and is therefore probably related to other factors, such as the moisture flux in the lowest layers.

3. Throughout the lifecycle of the medicane, the trajectory of the upper-level trough and the surface low are quite similar. While during the mature and decaying phase of the medicane, the upper-level trough likely does not significantly contribute anymore to the deepening and precipitation occurrence, it would be interesting to check through numerical simulations to what extent (i) the trajectories of the surface low and the trough are interdependant and (ii) the upper-level trough participates to the maintenance of the medicane.

4. Brightness temperatures of channel A-5, that peak at about $3.5 \mathrm{~km}$, reveal that these systems developed in connection with the presence of cold air in the midtroposphere, in particular downstream of the trough in the incipient stage of the storms. Some authors (e.g. Lagouvardos et al., 1999; Reale and Atlas, 2001; Reed et al., 2001; Fita et al., 2007, 2009; Davolio et al., 2009) have pointed out the existence of a warm core as for tropical cyclones. However, given the horizontal/vertical size of the medicanes compared to the horizontal/vertical resolution of AMSU-A, we have not been able to observe such a feature, but here again, finescale numerical simulations could complement this observational study.

Based on this investigation, one can surmise that a precise forecast of medicanes (associated precipitation and trajectory) relies at least on a very good representation of the upper-level synoptic conditions (in terms of amplitude, position, trajectory) and of its phasing with the mid-troposphere situation. It indirectly confirms the role of upper level structures for short range forecasting of sub-synoptic vortices over the Mediterranean Sea, as shown e.g. by Argence et al. (2009), that demonstrated that rather minor perturbations in the depth of the upper-level trough at the initial stage of cyclogenesis could propagate and intensify during numerical simulations, strongly impacting the forecast of a medicane.

In addition, the diagnostics presented here could be used to evaluate the quality of numerical simulations of medicanes through a model-to-satellite approach. Such an evaluation would involve the numerical simulation of brightness temperatures at AMSU-A and AMSU-B/MHS wavelengths using a radiative transfer model and their comparison to the observations (e.g. Chaboureau et al., 2000, 2002). It would thus allow an assessment of a model's physical parameterizations and representation of the upper-levels.

Note also that there are at present time five platforms carrying AMSU radiometers (even six if one considers NOAA-17 for which AMSU-B is still available despite instrument failure of most AMSU-A channels after November 2003), so that the precipitation/convection areas associated to recent medicanes throughout their lifetime could be even more accurately described.

Finally, the present study supports the need to collect high-resolution data in areas upstream of the Mediterranean within the future $\mathrm{HyMeX}$ (Hydrological Cycle in the Mediterranean eXperiment) field campaign (http://www.cnrm.meteo.fr/hymex/). 
Acknowledgements. This study was sponsored by the French Ministry of Research through the project ANR-VMC2007 "Forecast and projection in climate scenario of Mediterranean intense events: Uncertainties and Propagation on environment" (MedUP) and by the Chaire de Développement Durable of the Ecole Polytechnique. AMSU data was obtained through the French Mixed Service Unit ICARE.

Edited by: A. Mugnai

Reviewed by: two anonymous referees

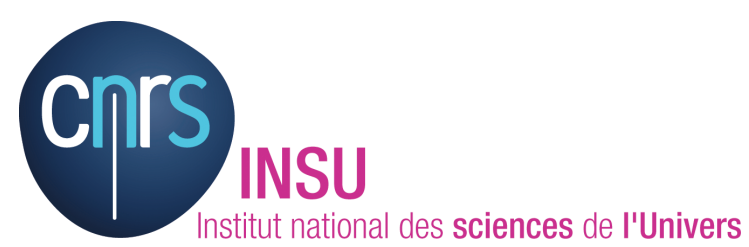

The publication of this article is financed by CNRS-INSU.

\section{References}

Alpert, P., Tsidulko, M., and Izigsohn, D.: A shallow short-lived meso-beta cyclone over the Gulf of Antalya, eastern Mediterranean, Tellus A, 51, 249-262, 1999.

Argence, S., Lambert, D., Richard, E., Chaboureau, J.-P., Arbogast, P., and Maynard, K.: Improving the numerical prediction of a cyclone in the Mediterranean by local potential vorticity modifications, Q. J. Roy. Meteorol. Soc., 134, 1287-1296, 2009.

Billing, H., Haupt, I., and Tonn, W.: Evolution of a hurricane-like cyclone in the Mediterranean Sea, Beitr. Phys. Atmos., 56, 508510, 1983.

Blechschmidt, A. M., Bakan, S., and Grassl, H.: Large scale atmospheric circulation patterns during polar low events over the Nordic Seas, J. Geophys. Res., 114, D06115, doi:10.1029/2008JD010865, 2009.

Businger, S. and Reed, R. J.: Cyclogenesis in cold air masses, Weather Forecast., 4, 133-156, 1989.

Chaboureau, J.-P. and Claud, C.: Satellite-based climatology of Mediterranean cloud systems and their association with large-scale circulation, J. Geophys. Res., 111, D01102, doi:10.1029/2005JD006460, 2006.

Chaboureau, J. P., Cammas, J. P., Mascart, P., Pinty, J. P., Claud, C., Roca, R., and Morcrette, J. J.: Evaluation of a cloud system life-cycle simulated by Meso-NH during FASTEX using METEOSAT radiances and TOVS-3I cloud retrievals, Q. J. Roy. Meteorol. Soc., 126, 1735-1750, 2000.

Chaboureau, J. P., Cammas, J. P., Mascart, P., Pinty, J. P., and Lafore, J. P.: Mesoscale model cloud scheme assessment using satellite observations, J. Geophys. Res., 107, 4301, doi:10.1029/2005JD006460, 2002.

Claud, C., Duchiron, B., and Terray, P.: Associations between largescale atmospheric circulation and polar low developments over the North Atlantic during winter, J. Geophys. Res., 112, D12101, doi:10.1029/2006JD008251, 2007.
Davolio, S., Miglietta, M. M., Moscatello, A., Pacifico, F., Buzzi, A., and Rotunno, R.: Numerical forecast and analysis of a tropical-like cyclone in the Ionian Sea, Nat. Hazards Earth Syst. Sci., 9, 551-562, doi:10.5194/nhess-9-551-2009, 2009.

Doswell, C. A., Ramis, C., Romero, R., and Alonso, S.: A diagnostic study of three heavy precipitation episodes in the western Mediterranean region, Weather Forecast., 13, 102-124, 1998.

Emanuel, K.: Genesis and maintenance of "Mediterranean hurricanes", Adv. Geosci., 2, 217-220, doi:10.5194/adgeo-2-2172005, 2005.

Ernst, J. A. and Matson, M.: A Mediterranean tropical storm?, Weather, 38, 332-337, 1983.

Fehlmann, R., Quadri, C., and Davies, H. C.: An Alpine rainstorm: Sensitivity to the mesoscale upper-level structures, Weather Forecast., 15, 4-28, 2000.

Fita, L., Romero, R., Luque, A., Emanuel, K., and Ramis, C.: Analysis of the environments of seven Mediterranean tropicallike storms using an axisymmetric, nonhydrostatic, cloud resolving model, Nat. Hazards Earth Syst. Sci., 7, 41-56, doi:10.5194/nhess-7-41-2007, 2007a.

Fita, L., Romero, R., and Ramis, C.: Objective quantification of perturbations produced with a piecewise PV inversion technique, Ann. Geophys., 25, 2335-2349, doi:10.5194/angeo-252335-2007, 2007b.

Funatsu, B. M., Claud, C., and Chaboureau, J. P.: Potential of Advanced Microwave Sounding Unit to identify precipitating systems and associated upper-level features in the Mediterranean region: Case studies, J. Geophys. Res., 112, D17113, doi:10.1029/2006JD008297, 2007.

Funatsu, B. M., Claud, C., and Chaboureau, J. P.: A 6-year AMSUbased climatology of upper-level troughs and associated precipitation distribution in the Mediterranean region, J. Geophys. Res., 113, D15120, doi:10.1029/2008JD009918, 2008.

Funatsu, B. M., Claud, C., and Chaboureau, J. P.: Comparison between the large-scale environments of moderate and intense precipitating systems in the Mediterranean region, Mon. Weather Rev., 137, 3933-3959, doi:10.1175/2009MWR2922.1, 2009.

Gaertner, M. A., Jacob, D., Gil, V., Dominguez, M., Padorno, E., Sanchez, E., and Castro, M.: Tropical cyclones over the Mediterranean Sea in climate change simulations, Geophys. Res. Lett., 34, L14711, doi:10.1029/2007GL029977, 2007.

Greenwald, T. J. and Christopher, S. A.: Effect of cold clouds on satellite measurements near $183 \mathrm{GHz}$, J. Geophys. Res., 107(D13), 4170, doi:10.1029/2000JD000258, 2002.

Heinemann, G. and Claud, C.: Report of a workshop on "Theoretical and observational studies of polar lows" of the European Geophysical. Society Polar Lows Working Group, B. Am. Meteorol. Soc., 78, 2643-2658, 1997.

Homar, V., Romero, R., Ramis, C., and Alonso, S.: Numerical study of the October 2000 torrential precipitation event over eastern Spain: analysis of the synoptic-scale stationarity, Ann. Geophys., 20, 2047-2066, doi:10.5194/angeo-20-2047-2002, 2002.

Homar, V., Romero, R., Stensrud, D., Ramis, C., and Alonso, S.: Numerical diagnosis of a small, quasi-tropical cyclone over the western Mediterranean: Dynamical vs. boundary factors, Q. J. Roy. Meteor. Soc., 129, 1469-1490, 2003. 
Hong, G., Heygster, G., Miao, J., and Kunzi, K.: Detection of tropical deep convective clouds from AMSU-B water vapor channels measurements, J. Geophys. Res., 110, D05205, doi:10.1029/2004JD004949, 2005.

Lagouvardos, K., Kotroni, V., Nickovic, S., Jovic, D., and Kallos, G.: Observations and model simulations of a winter sub-synoptic vortex over the central Mediterranean, Meteorol. Appl., 6, 371383, 1999.

Luque, A., Fita, L., Romero, R., and Alonso, S., Tropical-like Mediterranean storms: an analysis from satellite, Proceeding of the Joint EUMETSAT/AMS Conference, Amsterdam, Netherlands, 2007.

Mo, T.: Calibration and validation of the NOAA-18 Microwave radiometers, IEEE MicroRad, 24-28, 2006.

Moscatello, A., Miglietta, M. M., and Rotunno, R.: Observational analysis of a Mediterranean "hurricane" over southeastern Italy, Weather, 63, 306-311, 2008a.

Moscatello, A., Miglietta, M. M., and Rotunno, R.: Numerical analysis of a Mediterranean "hurricane" over southeastern Italy, Mon. Weather Rev., 136, 4373-4397, 2008b.

Pytharoulis, I., Craig, G. C., and Ballard, S. P.: The hurricanelike Mediterranean cyclone of January 1995, Meteorol. Appl., 7, 261-279, 2000.
Rasmussen, E. and Zick, C.: A subsynoptic vortex over the Mediterranean with some resemblance to polar lows, Tellus A, 39, 408425, 1987.

Reale, O. and Atlas, R.: Tropical Cyclone-like vortices in the Extratropics: Observational Evidence and synoptic analysis, Weather Forecast., 16, 7-34, 2001.

Reed, R. J., Kuo, Y.-H., Albright, M. D., Gao, K., Gua, Y.-R., and Huang, W.: Analysis and modeling of a tropical-like cyclone in the Mediterranean Sea, Meteorol. Atmos. Phys., 76, 183-202, 2001.

Romero, R.: Sensitivity of a heavy rain producing western Mediterranean cyclone to embedded potential vorticities anomalies, Q. J. Roy. Meteorol. Soc., 127, 2559-2597, 2001.

Saunders, R. W., Matricardi, M., Brunel, P., English, S., Bauer, P., O'Keeffe, U., Francis, P., and Rayer, P.: RTTOV-8 Science and Validation Report, Numer. Weather Predic. Satell. Appl. Facil., Exeter, UK, Technical Report, 41 pp., 2005.

Zahn, M. and von Storch, H.: A long-term climatology of North Atlantic polar lows, Geophys. Res. Lett., 35, L22702, doi:10.1029/2008GL035769, 2008. 